\title{
Comparative analysis on dynamic behavior of two HMA railway substructures
}

\author{
Mingjing $\mathrm{FANG}^{1,2^{*}}$, Yanjun $\mathrm{QIU}^{2}$, Jerry G. ROSE${ }^{3}$, Randy C. $\mathrm{WEST}^{1}$, Changfa $\mathrm{AI}^{2}$ \\ 1.National Center for Asphalt Technology (NCAT), College of Engineering, Auburn University, Auburn, AL 36830-5577, USA \\ 2.School of Civil Engineering, Southwest Jiaotong University, Chengdu 610031, China \\ 3. College of Engineering, Civil Engineering Department, University of Kentucky, Lexington, KY 40506-0281, USA
}

\begin{abstract}
A numerical analysis using a finite element program was performed on three structures: hot mix asphalt (HMA) reinforced trackbed (RACS-1), HMA directly supported trackbed (RACS-2), and traditional Portland Cement Concrete (PCC) slab track (SlabTrack). Although the comprehensive dynamic responses of RACS-1 were similar with SlabTrack, HMA layer can positively affect the stress distributions. In particular, the horizontal stresses indicate that the resilience of RACS-1 was improved relative to SlabTrack. In addition, HMA reinforced substructure has the capacity to recover the residual vertical deformation. The effective depth for weakening dynamic loadings is mainly from 0 to $2 \mathrm{~m}$, this being especially true at $0.5 \mathrm{~m}$. The results from the analysis show that HMA is a suitable material for the railway substructure to enhance resilient performance, improve the stress distribution, weaken dynamic loading, and lower the vibration, especially at the effective depth of $2 \mathrm{~m}$. The HMA constructed at the top of the stone subbase layer allows the vertical modulus a smooth transition. In terms of the comprehensive dynamic behaviors, RACS-1 is better than SlabTrack, while the results for RACS-2 are inconclusive and require further research.
\end{abstract}

Key words: high-speed railway; HMA; railway substructure; FEM analysis

(C) 2011 JMT. All rights reserved.

\section{Introduction}

A round the world there is a trend for both highspeed and heavy-axle loadings trains, a trend which requires stronger and smoother railway substructures [1]. For the traditional and regular railway trackbed, the pulverization of granular ballast and settlement of the substructure demands extensive maintenance to meet the safety requirements for high speeds [2]. Ballastless tracks have been widely used for high-speed railway construction by many countries like Japan [3] and Germany [4] to deal with those problems. These ballastless tracks often adopt Portland cement concrete (PCC) to distribute loads from rails to the subgrade. However, these PCC railway substructures also tend to have significant maintenance issues such as cracking, thus, making it difficult to maintain the track, as well as problems with noise and vibration [5-6].

Visco-elastic characteristics with sufficient strength and resilience [7] of hot mix asphalt (HMA) could make it better suited for the requirements of high-speed rail-

Received Jul. 23, 2010; revision accepted Jan. 26, 2011

${ }^{*}$ Corresponding author. Tel.: +86-28-87634347

Email: mingjingfang@hotmail.com (M.J. FANG)

doi: 10.3969/j.issn.2095-087X.2011.01.005 way substructures. Japan [8], Germany [9], Italy [10] and the US [11-12] have conducted considerable research, including theoretical analysis, as well as laboratory and field tests on railways with HMA substructures. In China, HMA is currently used as a waterproof material to cover the top of both sides of the subgrade surface and along the middle of parallel railway lines. It is also called surface asphalt mixture as impermeable (SAMI) [13-14]. HMA is being considered as a structural layer, and the related research, supported by National Natural Science Foundation of China (NSFC), is just in its early stages.

This paper summarizes the basic calculations considered as part of the NSFC project for the research pertaining to model testing in the lab. Dynamic responses of three railway substructures were calculated using the finite element method (FEM) program ABAQUS [15]. The railway substructures were the Japanese ballastless track design, known as concrete slab track named SlabTrack, and two structures named RACS-1 and RACS-2. These last two structures had an HMA layer at different positions in the substructures. The horizontal stresses, vertical deformation, and acceleration were analyzed. 


\section{DoI:10.106tives}

Dynamic behaviors of HMA substructures are compared to the corresponding responses from the slab track.

The schematic cross-sections of the three structures are shown in Fig. 1. Fig. 1(a), referred to as RACS-1, uses an HMA layer between a PCC base and the crushed stone subbase. Fig. 1(b), RACS-2, uses an HMA layer to replace the PCC base. Fig. 1(c) is the design of SlabTrack as the reference of this analysis. The full crosssection with parallel track was modeled to avoid the complicated processing of symmetric boundary conditions because of non-linear materials like HMA. Moreover, the adjacent train loadings affect each other for the real dynamic responses tested in field.

\section{Finite element method models}

\subsection{Parameters of the layered railway substructures}

Each concrete slab is $4930 \mathrm{~mm}$ long, and the distance between two fasteners is $600 \mathrm{~mm}$, excluding the gap at the joint (usually $70 \mathrm{~mm}$ ). In total, $200 \mathrm{MPa}$ was used as the dynamic modulus assumed to be the same as the resilient modulus due to the high stiffness for the mortar layer, which is for the purpose of adjusting and made from asphalt emulsion, cement, fine aggregate, water, and some special additives like aluminite powder.

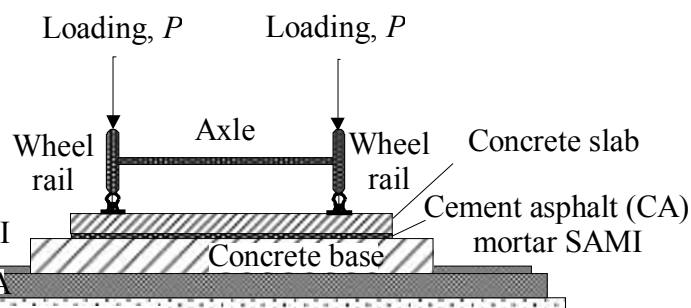
HMA

Gradation crushed stone

Subgrade

(a) ACRS-1

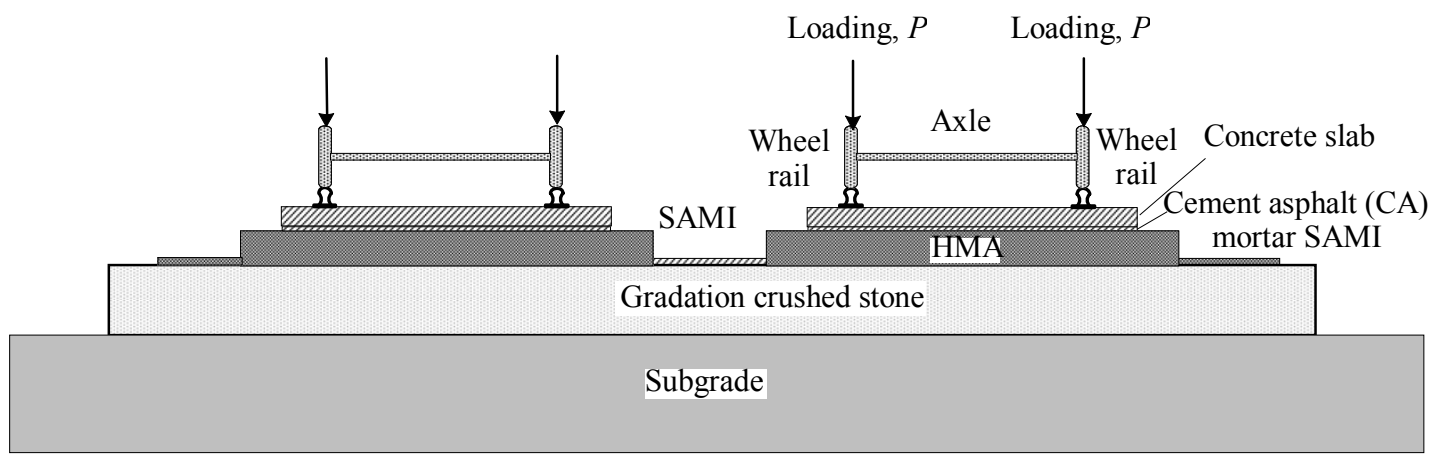

(b) ACRS-2

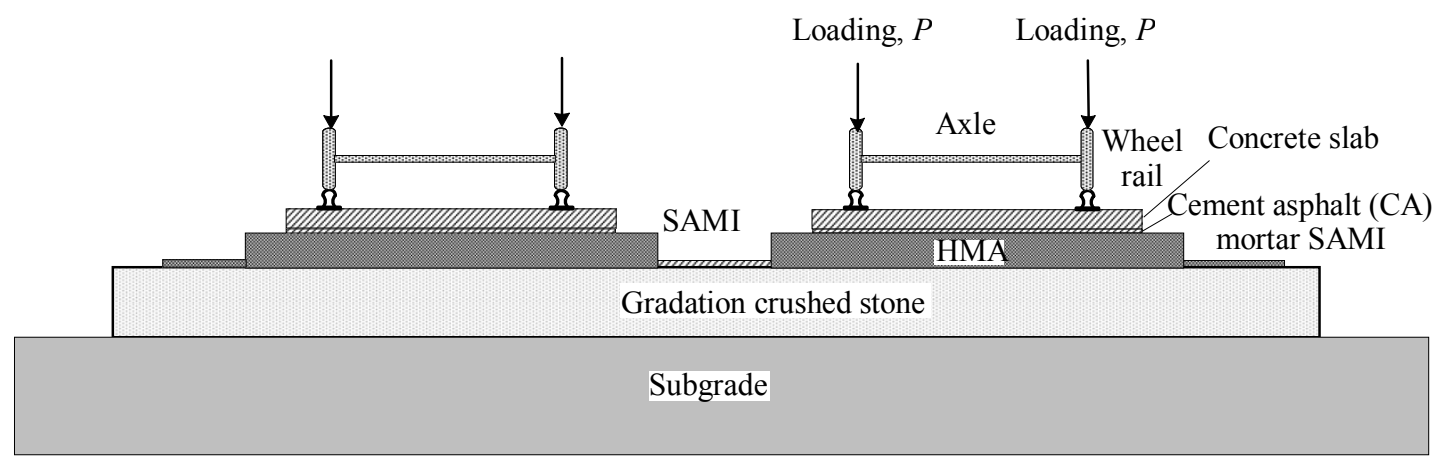

(c) SlabTrack

Fig. 1 Schematic cross-sections of the three structures 
The thickness of the HMA layer was $200 \mathrm{~mm}$, and POI widths of PFA3325733 RACS-1 and RACS-2 were the same as the crushed stone subbase and PCC base, respectively. The HMA dynamic modulus was also considered to be $200 \mathrm{MPa}$ using the vulnerable condition to represent its stiffness during the warmest months [16]. The SAMI layer was not considered as part of the load carrying structure. For the subgrade bed, a dynamic modulus of $150 \mathrm{MPa}$ was used for the top of the layer and $120 \mathrm{MPa}$ for the bottom of the layer. All of the element types were solid. The parameters for the calculation are listed in Table 1.

\subsection{Assembly of numerical models}

The bottom of each model was constrained in all six degrees of freedom (DOF). Symmetric boundary condition was applied for the cut section along the rail direction. There were no other constraints for the models. For simplicity, a continuous condition for interlayer contact was used. The mesh of models was generated by an 8- node inducing integrated element, C3D8R, because of its higher accuracy with lower computational cost. Fig. 2(a) shows the schematic model after meshing.

\subsection{Scheme of load and calculation}

\subsubsection{Load selection}

For simplicity, a uniaxial uniform pressure of $125 \mathrm{kN}$ was used on each side of the rail track to simulate the load passing from rail and fastener to slab track; each loading area was $100 \mathrm{~mm} \times 200 \mathrm{~mm}$ and $1435 \mathrm{~mm}$ was used for the central spacing. The sphere of dynamic influence was in the area of nine sleepers in a row and each was placed at an interval of $0.6 \mathrm{~m}(d)$. Assume the train speed is $200 \mathrm{~km} / \mathrm{h}(v)$, and the loading time difference $\mathrm{d} t$ to a single sleeper is $3600 \mathrm{~d} / \nu=0.0108 \mathrm{~s}$. Although 0.0054 seconds was adopted as the time step of this numerical analysis, the loading-time curves shown in Fig. 2(b) after interpolating were used to improve the calculating accuracy.

Table 1 Modeling parameters

\begin{tabular}{|c|c|c|c|c|c|c|c|}
\hline \multirow{2}{*}{ Structural layer } & \multirow{2}{*}{\multicolumn{2}{|c|}{$\begin{array}{c}\text { Geometry } \\
\text { parameters }^{*}(\mathrm{~m})\end{array}$}} & \multirow{2}{*}{ Materials } & \multicolumn{4}{|c|}{ Properties } \\
\hline & & & & $\begin{array}{l}\text { Modulus } \\
(\mathrm{MPa})\end{array}$ & $\begin{array}{l}\text { Poisson } \\
\text { ratio }\end{array}$ & $\begin{array}{l}\text { Density } \\
\left(\mathrm{kg} / \mathrm{m}^{3}\right)\end{array}$ & $\begin{array}{l}\text { Damping } \\
\text { ratio }\end{array}$ \\
\hline Concrete slab & $\begin{array}{c}\text { RACS-1 } \\
\text { RACS-2 } \\
\text { SlabTrack }\end{array}$ & $\begin{array}{l}2.4 \mathrm{w} \\
0.19 \mathrm{~h}\end{array}$ & Cement concrete & $3.6 \times 10^{4}$ & 0.16 & 2450 & 0.03 \\
\hline Mortar & $\begin{array}{c}\text { RACS-1 } \\
\text { RACS-2 } \\
\text { SlabTrack }\end{array}$ & $\begin{array}{l}2.4 \mathrm{w} \\
0.05 \mathrm{~h}\end{array}$ & CA sand mortar & 200 & 0.3 & 2050 & 0.035 \\
\hline Concrete base & $\begin{array}{c}\text { RACS-1 } \\
\text { SlabTrack }\end{array}$ & $\begin{array}{l}3.0 \mathrm{w} \\
0.3 \mathrm{~h}\end{array}$ & Cement concrete & $3.25 \times 10^{4}$ & 0.167 & 2450 & 0.03 \\
\hline \multirow{2}{*}{ HMA } & RACS-1 & $\begin{array}{l}8.8 \mathrm{w} \\
0.2 \mathrm{~h}\end{array}$ & \multirow{2}{*}{ Asphalt mixture } & \multirow{2}{*}{$200^{* *}$} & \multirow{2}{*}{0.45} & \multirow{2}{*}{2360} & \multirow{2}{*}{0.055} \\
\hline & RACS-2 & $\begin{array}{l}3.0 \mathrm{w} \\
0.3 \mathrm{~h}\end{array}$ & & & & & \\
\hline \multirow{2}{*}{ Stone subbase } & RACS-1 & $\begin{array}{l}13.2 \mathrm{w} \\
0.2 \mathrm{~h}\end{array}$ & \multirow{2}{*}{$\begin{array}{l}\text { Graded broken } \\
\text { stone/sand gravel }\end{array}$} & \multirow{2}{*}{150} & \multirow{2}{*}{0.3} & \multirow{2}{*}{2000} & \multirow{2}{*}{0.045} \\
\hline & $\begin{array}{c}\text { RACS-2 } \\
\text { SlabTrack }\end{array}$ & $\begin{array}{l}13.2 \mathrm{w} \\
0.4 \mathrm{~h}\end{array}$ & & & & & \\
\hline Subgrade & $\begin{array}{c}\text { RACS-1 } \\
\text { RACS-2 } \\
\text { SlabTrack }\end{array}$ & $\begin{array}{l}13.2 \mathrm{w} \\
0.2 \mathrm{~h}\end{array}$ & $\begin{array}{l}\text { A, B filler, } \\
\text { improved soil }\end{array}$ & 120 & 0.35 & 1900 & 0.039 \\
\hline Bank beneath bed & $\begin{array}{c}\text { RACS-1 } \\
\text { RACS-2 } \\
\text { SlabTrack }\end{array}$ & $\begin{array}{c}24.6 \mathrm{w} \\
3.0 \mathrm{~h}\end{array}$ & $\begin{array}{l}\text { A, B, C filler, } \\
\text { improved soil }\end{array}$ & 60 & 0.4 & 1800 & 0.035 \\
\hline
\end{tabular}

Note: ${ }^{*}$ full section, $13.2 \mathrm{~m}$ for width of stone subbase layer, 1:1.5 slope of embankment; ${ }^{* *}$ average modulus in high temp. 


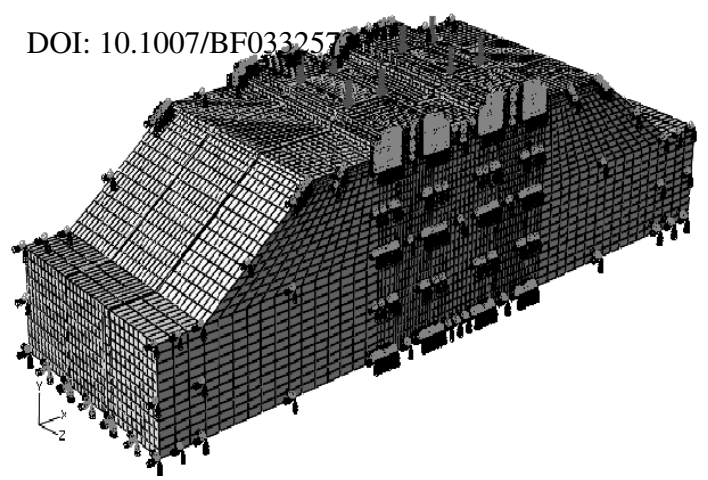

(a) Calculating model after meshing

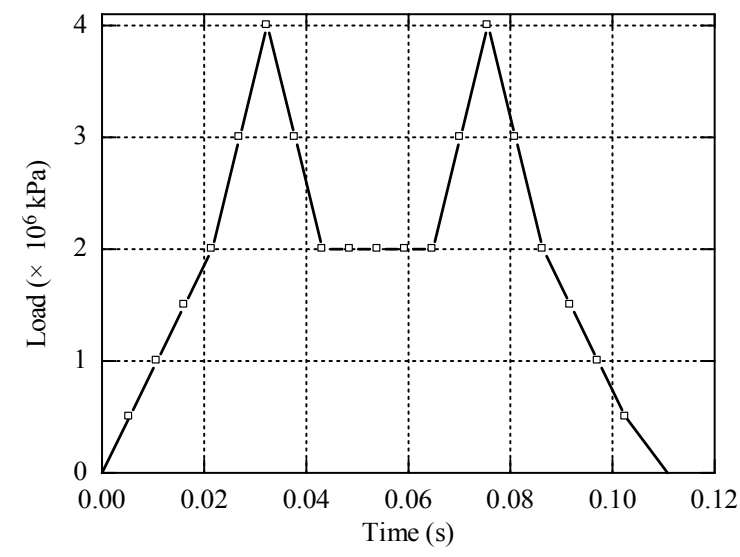

(b) Simplified loading-time curve

Fig. 2 Preparations for numerical modeling

\subsubsection{Data extracting scheme}

Six typical data extracting paths were used for the following responses analysis. Along wide direction, path 1 , path 2 , path 3 , path 4 , and path 5 were on the bottom of slab, CA mortar layer, base (HMA layer if RACS-2), HMA layer (crushed stone subbase if RACS1) and crushed stone layer respectively. Path 6 was along the vertical direction passed through one of inner wheel loading points.

\section{Results analysis}

\subsection{Horizontal dynamic stress}

The horizontal dynamic stress-distance relationships along paths 1-5 are shown in Fig. 3.

\subsubsection{Horizontal dynamic stresses at the bottom of slab}

The transversal and longitudinal dynamic stresses along path 1 are shown in Fig. 3(a). The horizontal stress of RACS-2 was the largest among the three structures. The transverse tensile stresses were generated on both two sides about $0.4 \mathrm{~m}$ in length along wide direc- tion both RACS-1 and SlabTrack structures. The longitudinal stresses at the bottom of the slab were all compressive, because the composite modulus of RACS-2 was the smallest among the three structures. The maximum horizontal tensile stress on the bottom of slab for RACS-1 was greater than that of SlabTrack, causing the flexibility of HMA reinforced subgrade to be improved. This is similar to increasing the stiffness of a spring.

\subsubsection{Horizontal stresses at the bottom of $C A$ sand mortar}

The transversal and longitudinal dynamic stresses found along path 2 are shown in Fig. 3(b). The pattern of the horizontal dynamic stresses for all three structures along path 2 was similar. Stress magnitudes were greatest along the sides and smaller in the middle. The general stress level for RACS-2 is obviously larger than the others. On the ends of the layer, the transverse and longitudinal stresses of RACS-2 were about $10 \mathrm{kPa}$ and $16 \mathrm{kPa}$ respectively, whereas the horizontal stresses both of RACS-1 and SlabTrack were about $6 \mathrm{kPa}$. In the middle of the layer, the transverse and longitudinal stresses of RACS-2 were about $4 \mathrm{kPa}$ and $9 \mathrm{kPa}$, respectively, but negligible for the other two structures. This meant that using an HMA base layer caused the stress level of the CA layer to increase. This layer did not function as a load carrying element. From this result, the structures beneath the base layer should maintain sufficient stiffness; otherwise, the distribution of stress in the upper structure would seriously be negatively affected. This will also shorten the life of the whole structure, but the stiffness only can be changed in a limited scope to improve the stress distribution, which is clear if compared RACS-1 to SlabTrack.

\subsubsection{Horizontal stresses at the bottom of base}

The transverse and longitudinal dynamic stresses were computed along path 3 . At the base of the RACS-2 structure was the HMA layer; data curve is shown in Fig. 3(c). The graphs show that when HMA was used at the base to support the upper structure directly, the stress level was lower compared to the other two structures in either the transverse or longitudinal direction. The transverse and longitudinal stresses generated by RACS-2 were compressive in magnitude, and measured about $8 \mathrm{kPa}$ and $15 \mathrm{kPa}$, respectively. They were also relatively uniform along the horizontal direction. This is because the HMA layer, as a flexible base layer, does not have sufficient bearing capacity to "resist" the train loading passed to the crushed stone layer. For RACS-1 and SlabTrack, the bottom of the bases generates a significant transverse tensile stress and longitudinal com- 
pressive stress. The difference between the results of the BOI: $10.1007 / B F 93325733$ the transversal tensile stress of RACS-1 is greater than SlabTrack, while the longitudinal compressive stress of SlabTrack is greater than RACS-1. This shows that the base layer played an important role for bearing, and should have sufficient stiffness. In addition, the HMA reinforced subbase layer can positively affect the distribution of stress acting on the base, particularly the load-bearing function.

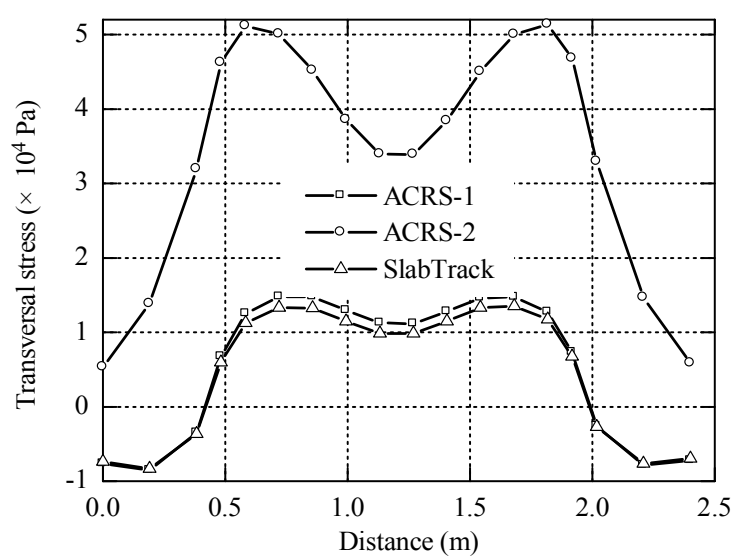

\subsubsection{Horizontal stresses on the bottom of HMA layer in RACS-1}

When HMA replaces the top part of the crushed stone layer in RACS-1, the path used to find the stresses acting on the three structures is along path 4 . The horizontal stresses of three structures were different and are shown in Fig. 3(d).

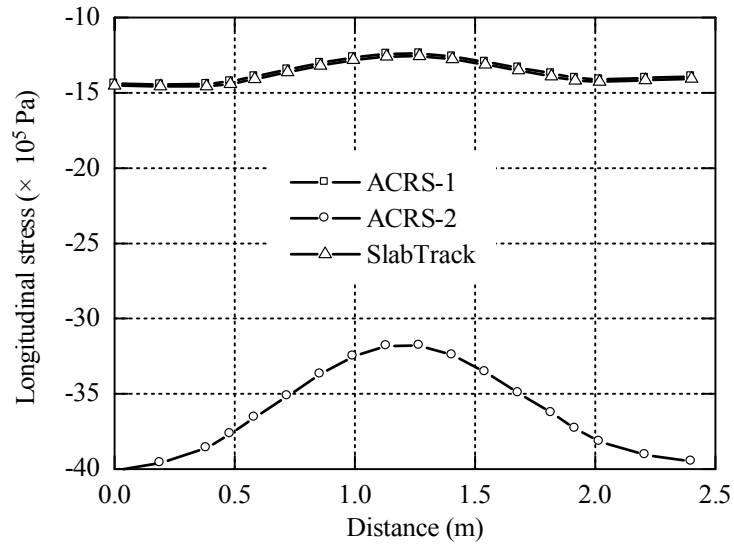

(a) Horizontal dynamic stresses-distance relationships along path 1
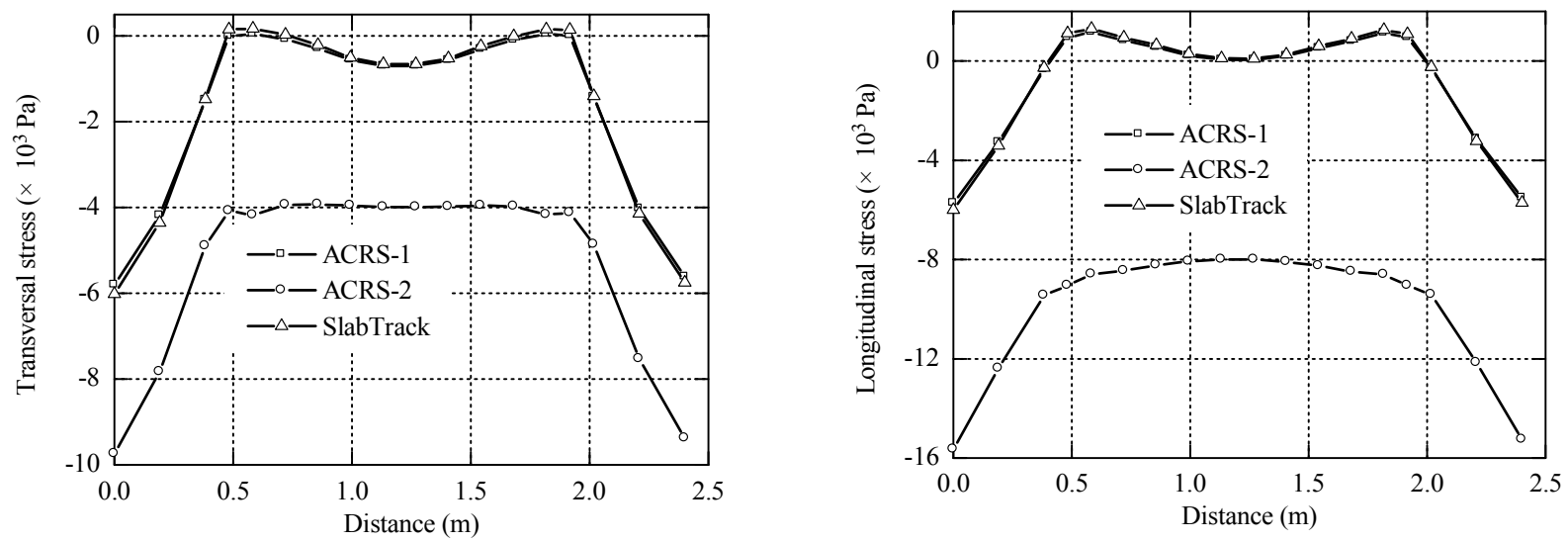

(b) Horizontal dynamic stresses-distance relationships along path 2
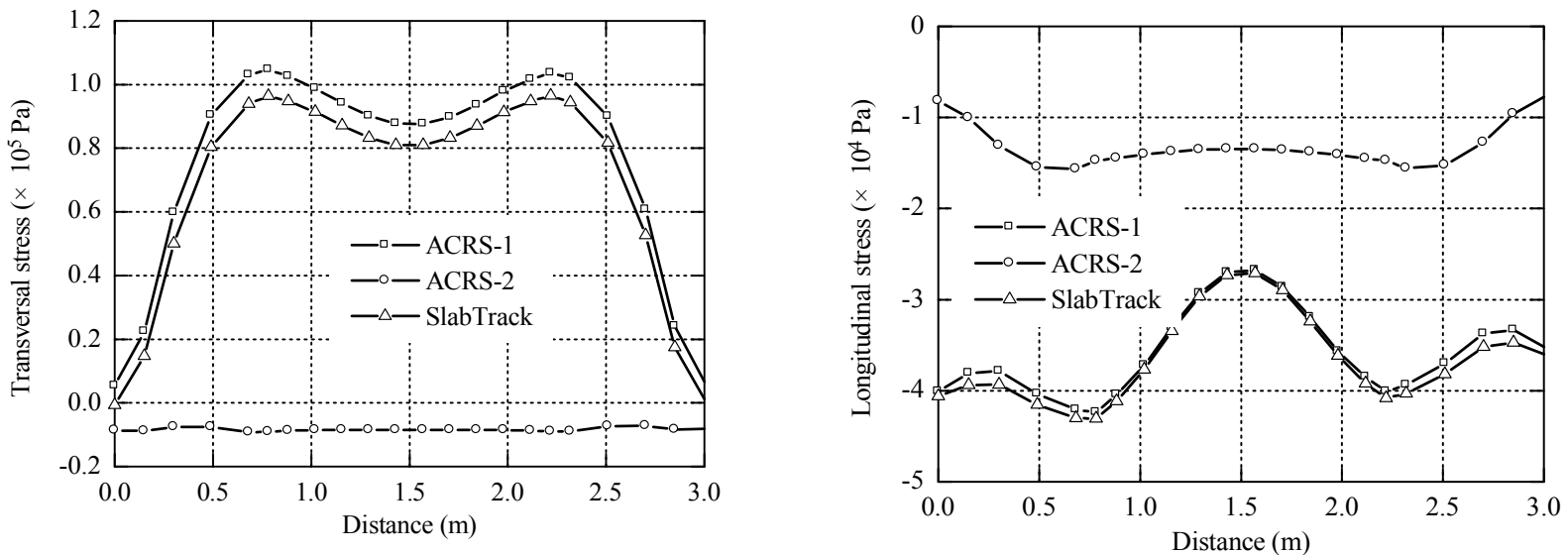

(c) Horizontal dynamic stresses-distance relationships along path 3 

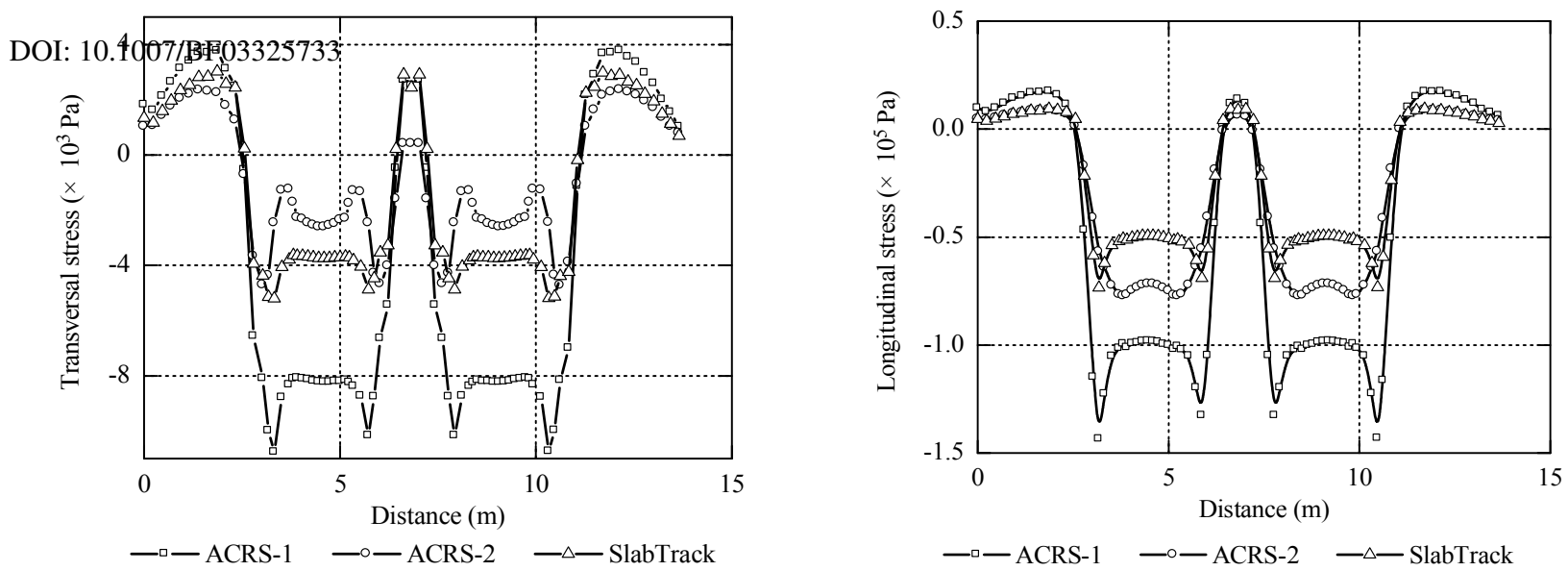

(d) Horizontal dynamic stresses-distance relationships along path 4
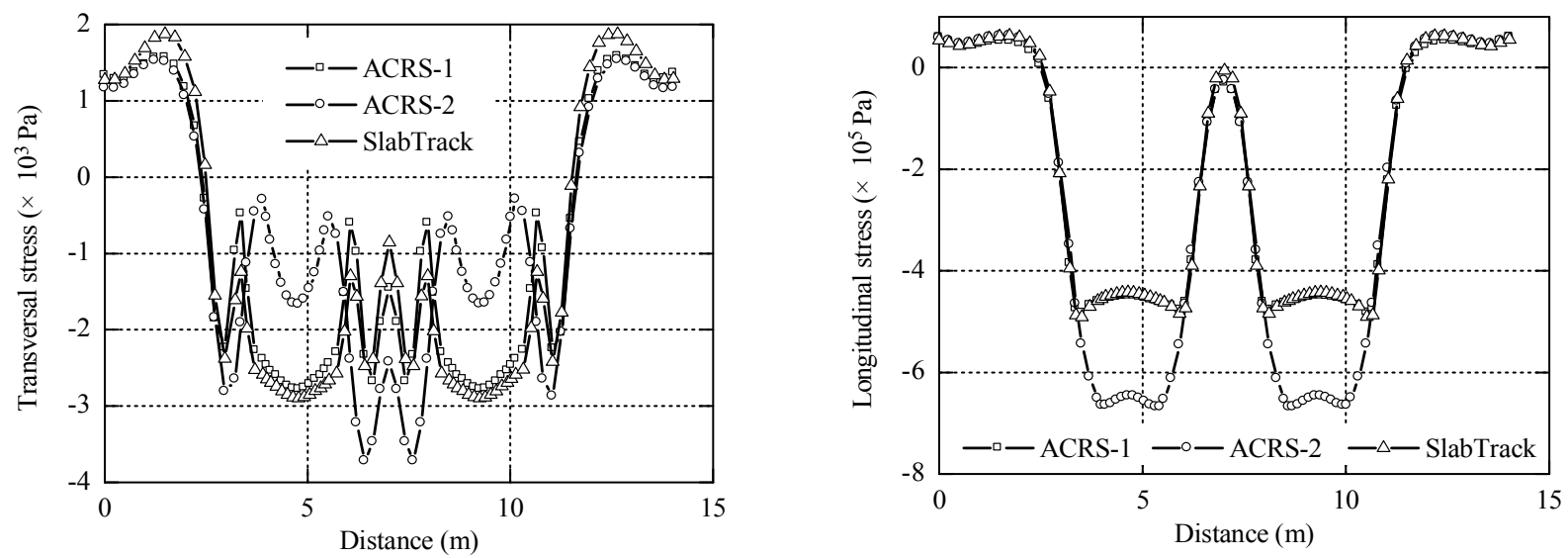

(e) Horizontal dynamic stresses-distance relationships along path 5

Fig. 3 Horizontal dynamic stresses-distance relationships (transverse stresses on left; longitudinal stresses on right)

From the figure, the stress tends to mutate at the edges of the base. This is due to the stress concentration caused by the cut effect of base edges. The transverse stresses under the wheel loadings was compressive in stress for RACS-1 and was measured to be about $7.5 \mathrm{kPa}$, which was distributed more evenly in the transverse direction. The transverse stress of RACS-2 showed characteristics with smaller values on both ends, but bigger in the middle (about $2.5 \mathrm{kPa}$ maximum along the path). The overall compressive stress of SlabTrack was about $3.5 \mathrm{kPa}$, and was distributed more evenly in the transverse direction. For longitudinal stresses, however, the average compressive stresses were $10 \mathrm{kPa}$ for RACS-1, $7.5 \mathrm{kPa}$ for RACS-2, and $5 \mathrm{kPa}$ for SlabTrack.

The analysis above shows that a subbase layer reinforced by HMA can positively improve the distribution of stresses on the track substructure regardless of transverse or longitudinal direction. Although there was a slight improvement of the stress in the longitudinal direction, the weakening capacity of the load resistance and the stress distribution was not stable for RACS-2. The HMA constructed at the top of the crushed stone layer can make the vertical modulus transition smoother, reducing the difference of modulus between layers of the PCC base and crushed stone subbase. By doing this, the distribution of the dynamic response of railway substructure will be more reasonable, lowering the stress level of subgrade surface, which has great significance to the sustained and stable long-term performance of the high-speed railway substructure.

\subsection{Vertical deformation}

The vertical deformation of three whole structures was generated at the maximum response value shown in Fig. 4. The results showed that RACS-2 generated the minimum dynamic tensile deformation and the maximum dynamic compressive deformation. As for the other two structures, the deformation of RACS-1 was slightly smaller than SlabTrack.

The maximum vertical dynamic deformation along path 6 from the loading central point on slab is shown in the Fig. 5(a). The central point load-time curves of the vertical deformation are drawn in Fig. 5(b). Fig. 5(a) 
shows the vertical deformation is decreasing rapidly with the depth. In 1 the depth from 0 (at the top of slab) to about $2 \mathrm{~m}$, the vertical deformation of RACS-2 was greater than the other two structures. The three would be very close if the depth was over than $2 \mathrm{~m}$. The related curve of RACS2 was more stable because HMA replaces the concrete as the base material, thus greatly weakening the upper composite modulus of the railway substructure.

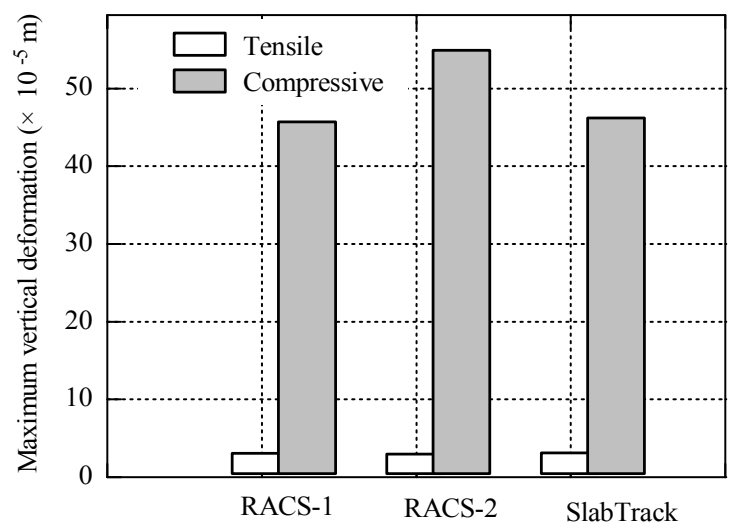

Fig. 4 Maximum vertical deformations

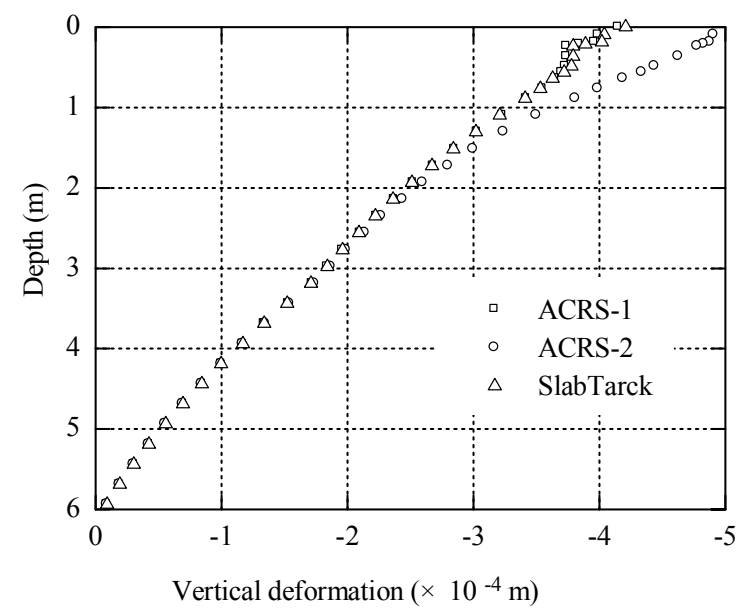

(a) Maximum vertical deformation-depth curves

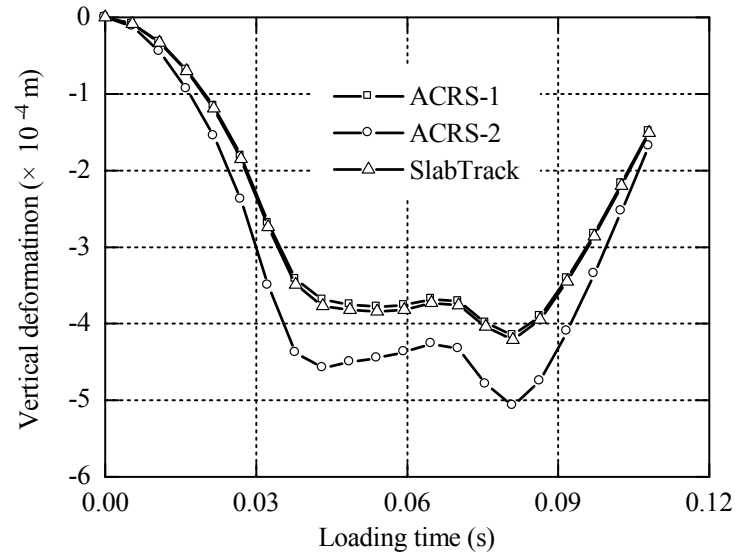

(b) Deformation-time curves

Fig. 5 Vertical deformation relationship with depth \& time
Fig. 5(b) shows the maximum vertical deformation of all three structures occurring at $0.081 \mathrm{~s}$. As for RACS-2, the deformation with the time was always greater than the other two structures, and RACS-1 was similar but slightly smaller than SlabTrack. The curve also shows that the remnant of vertical deformation occurs over the end of one circle for the loading time. Thus, for traditional slab track, it is very difficult to recover the remnant deformation because of the rigid concrete material. However, HMA, being a flexible and visco-elastic material, has good capacity for recovery, which would be very important to the longterm performance of the track structure, especially for the high-speed railway substructure.

\subsection{Vertical acceleration}

The maximum vertical acceleration responses of the three structures are shown in Fig. 6. The value of RACS-1 was less than SlabTrack, while peak accelerations for RACS-2 were about $45 \%$ greater than SlabTrack and RACS-1.

Fig. 7 shows the vertical acceleration relationship with depth and time. Along the depth direction from the center of the loading region, the maximum vertical accelerations of the three structures are shown in Fig. 7(a). The vertical acceleration-time relationship at the central load point on the slab is shown in Fig. 7(b).

Fig. 7(a) shows vertical acceleration with depth in the subgrade. The highest accelerations are near the top of the subgrade and they decrease sharply in the first two meters which is consistent with field measurements. Fig. 7(b) shows that the acceleration, especially the peak value of RACS-2, was significantly larger than the other two structures. Additionally, compared to SlabTrack the vertical acceleration of RACS-1 is slightly smaller.

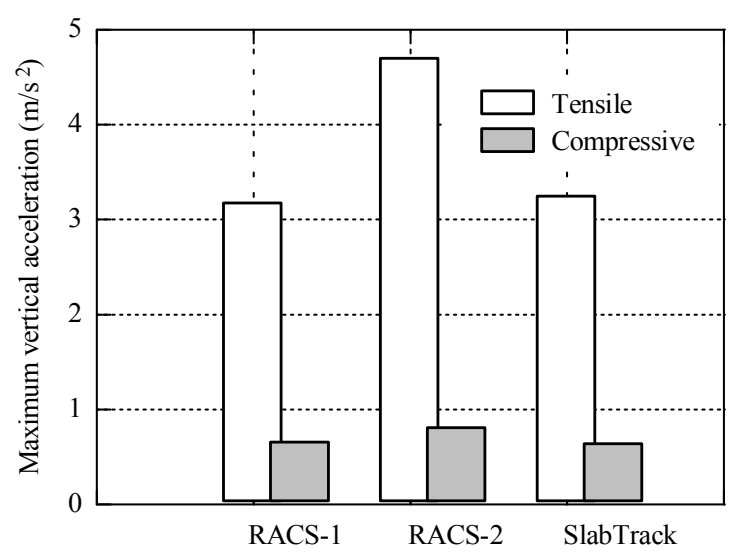

Fig. 6 Maximum vertical accelerations 


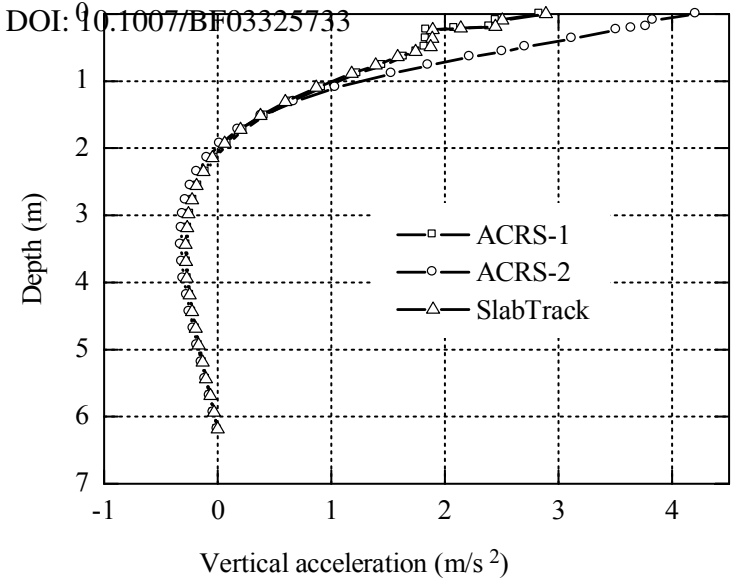

(a) Maximum vertical acceleration-depth curves

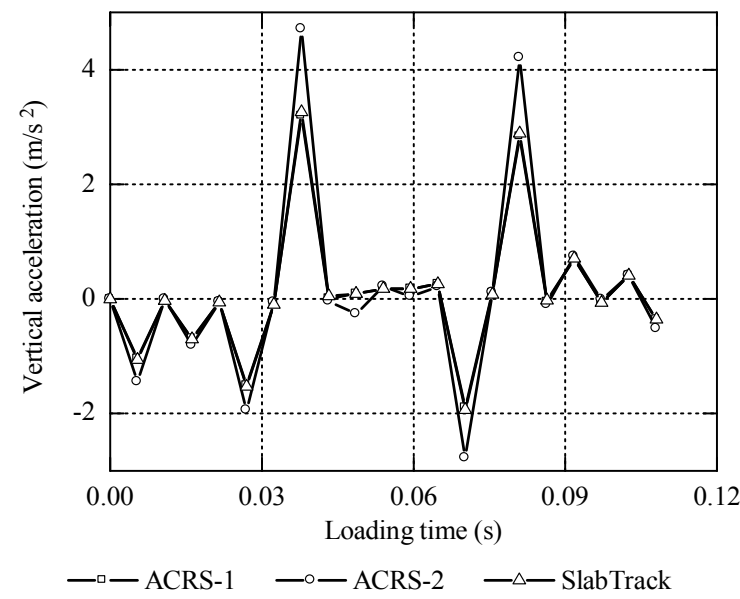

(b) Acceleration-time curves

Fig. 7 Vertical acceleration relationship with depth \& time

\section{Conclusions}

This numerical analysis viewed horizontal stresses, vertical deformation and vertical acceleration under the same loading and interlayer contact conditions. At the depth of $1 \mathrm{~m}$, the substructure of the slab track consists of PCC slab, CA sand mortar, PCC base and crushed stone layer. This was also the particularly effective depth to lower the vertical vibration by controlling the vertical acceleration. After analyzing and comparing the two HMA substructures to the traditional slab track, the following was found:

(1) The composite modulus of HMA reinforced subgrade can be improved relative to traditional slab track and HMA substructure has ability to recover the residual vertical deformation to a certain extent with circular loadings, which would be benefit for the long-term stability of the track structure.

(2) The comprehensive responses of RACS- 1 were similar with that of SlabTrack, but the HMA substruc- ture can positively affect the stress distribution. The stress distribution of RACS-1 at the stone subbase layer could be improved when compared to SlabTrack. The reasonable layer's combination, especially the modulus match of the substructure, will enhance the stress distribution.

(3) At a depth of about $2 \mathrm{~m}$, the vertical deformation of RACS-2 was always larger than RACS- 1 and SlabTrack, and RACS-1 had a slightly smaller deformation and acceleration in vertical direction than SlabTrack. The deformation of three structures was very close over $2 \mathrm{~m}$ deep. Thus, the depth from 0 to $2 \mathrm{~m}$, especially to $0.5 \mathrm{~m}$, is the important depth for weakening dynamic loading.

(4) At the depth of $2 \mathrm{~m}$, the vertical acceleration of the three structures were very close to 0 . However, RACS-2 was larger from 0 to $2 \mathrm{~m}$ deep, and its peak value of vertical acceleration was also slightly larger than the other two structures. Thus, the depth from 0 to $2 \mathrm{~m}$ was still the effective depth for vibration control.

The results show that HMA is a very suitable material for railway substructure to enhance resilient performance, improve stress distribution, weaken the dynamic loading, and lower vibration in the effective depth from 0 to $2 \mathrm{~m}$ especially to $0.5 \mathrm{~m}$ deep. The HMA constructed at the top of the stone subbase layer can make a smooth transition of the vertical modulus for each layer. From the comprehensive analysis of dynamic behavior, RACS-1 can be taken as a good option for practice, while RACS-2 needs further research before a conclusion made.

\section{Acknowledgements}

This paper is supported by NSFC project (No.50978222). The authors would like to thank Prof. Yongxing Wei for his assistance. Also, Ms. Rachel Nichols of University of Kentucky and Mr. Bill Minor of Auburn University are acknowledged for editing this draft and providing many useful suggestions.

\section{References}

[1] D. Adam, H. Brandl, I. Paulmichl, Dynamic aspects of rail tracks for high-speed railways, International Journal of Pavement Engineering, 2010, 11(4): 281-291.

[2] Q. Wang, Civil Engineering for High-Speed Railway, Chengdu: Southwest Jiaotong University Press, 1999 (in Chinese).

[3] S.D. Tayabji, D. Bilow, Concrete slab track state of the practice, Transportation Research Record: Journal of the Transportation Research Board, 2001(1742): 87-96.

[4] J. Eisenmann, G. Leykauf, L. Mattner, Recent developments in German railway track design, In: Proceedings of the Institution of Civil Engineers: Transport, 1994: 91-96. 
[5] C. Jiang, J. Fan, J. Wang, Key techniques of ballastless

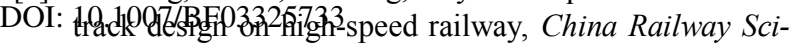
ence, 2004, 25(2): $42-47$ (in Chinese).

[6] C. Wang, Discussion and analysis for the factors of noise and vibration on high-speed railway, Railway Standard Design, 2000, 20(12): 61-62 (in Chinese).

[7] E.R. Brown, P.S. Kandhal, F.L.Roberts, et al., Hot Mix Asphalt Materials, Mixture Design, and Construction, 2nd edition, Maryland: NAPA Research and Education Foundation, 1996.

[8] P.F. Teixeira, A. López-Pita, C. Casas, et al., Improvements in high-speed ballasted track design: benefits of bituminous subballast layers, Transportation Research Record: Journal of the Transportation Research Board, 2006(1943): 43-49.

[9] B. Lechner, Developments in road pavement construction and railway track technology for a sustainable surface transportation infrastructure, In: Proceedings of the Eighth International Conference of Chinese Logistics and Transportation Professionals, Chengdu, 2008: 2656-2665.

[10] J.G. Rose, E.R. Brown, M.L. Osborne, Asphalt trackbed technology development: the first 20 years, Transportation Research Record: Journal of the Transportation Research Board, 2000(1713): 1-9.

[11] K. Chung, J. Rudjanakanoknad, M. J. Cassidy, Relation between traffic density and capacity drop at three freeway bottlenecks, Transportation Research-B, 2007, 41(1): 82-95.
[12] J.G. Rose, N.K. Agarwal, J. D. Brown, et al., Kentrack, a performance-based layered elastic railway trackbed structural design And analysis procedure: a tutorial, In: Proceedings of the 2010 Joint Rail Conference, Urbana, 2010: 73-110.

[13] M. Fang, Y. Wei, Y. Qiu, Impermeable design scheme of the subgrade surface of the ballastless track in highspeed railway, Subgrade Engineering, 2008, 5: 20-21 (in Chinese).

[14] Y. Qiu., Y. Wei, Mixing design and application of impermeable asphalt mixture in subgrade surface layer of ballastless railway track substructure, Journal of the China Railway Society, 2008, 30(5): 85-90 (in Chinese).

[15] Y. Shi, Y. Zhou, Finite Analysis and Example of ABAQUS, Beijing: China Machine Press, 2006 (in Chinese).

[16] J.G. Rose, B. Su, Comparisons of railroad track and substructure computer model predictive stress value and inSitu stress measurements, In: Proceedings of the 2004 AREMA Annual Conference, Nashville, 2004.

[17] W. Huang, Y. Lu, S. Luo, et al., Dynamic stress measurement and analysis of subgrade-culvert transition section on Qinhuangdao-Shenyang passenger special line, Journal of Southwest Jiaotong University, 2005, 40(2): 220-223 (in Chinese).

(Editor: Yao ZHOU) 